\title{
Review
}

\section{On the way to the automated (blood) glucose regulation in diabetes: the dark past, the grey present and the rosy future*}

\author{
XII Congress of the International Diabetes Federation, Madrid, 22-28 September 1985
}

\author{
E.F.Pfeiffer \\ University of Ulm, Ulm, FRG
}

\begin{abstract}
Surmmary. The development of the artificial pancreas represents an important step forward in modern diabetology. The practical and theoretical findings obtained by its application to Type 1 (insulin-dependent) diabetic patients has given new insights into modes of insulin secretion, pathophysiology of diabetes mellitus, and new forms of treatment, i.e. the development of portable insulin pumps and intensified conventional insulin therapy. All of these therapies provided better results than conventional insulin administration. However, there is no doubt that the restoration of normoglycaemia in a real sense is obtainable only by an implantable artificial pan-
\end{abstract}

creas or pancreas transplantation. The development of the implantable artificial pancreas, on the other hand, is dependent upon the development of a reliably working permanently implantable glucose sensor. The first attempts in that direction have opened new vistas as to the differences between blood and interstitial tissue glucose measurements, displaying different modes of regulation under normal and pathologic conditions. A number of barriers have to be overcome until the final goal has been attained: to obtain, by automated blood glucose control, narrow glycaemic fluctuations of the normal subject, and to prevent, hopefully, relentless diabetic complications.
According to Henri Bergson, the contribution of Claude Bernard to the philosophical sciences consisted of the development of the theory of experimental methodology per se. In a similar fashion as Descartes had elaborated, for the 17 th and 18th century, the "Discours de la Méthode" for the abstract sciences, Claude Bernard laid for the 19th century, in his "Introduction à la Médecine Expérimentale" the theoretical basis for all past, present, and future "biomedical", or in Bernard's style "Physiological Research".

He was a man who made one important discovery after the other, and afterwards when asking how this new observation came about, went the way back from the single fact to the general explanation. Without that constant dialogue between experimental - or clinical observation and theoretical explanation, neither fact nor theory alone are sufficient for providing further knowledge, be it as progress or regress in form of correction.

\footnotetext{
* This article represents a reproduction of the Claude Bernard Lecture 1985 of the European Association for the Study of Diabetes, [published in: Serrano-Rios M, Lefèbvre PJ (eds) (1986) Diabetes 1985. Excerpta Medica International Congress Series No. 700. Excerpta Medica, Amsterdam New York Oxford, pp 56-83 - with kind permission of the publisher and the editors]. The manuscript has not been subjected to the Diabetologia editorial process. The Editor
}

This conclusion is best illustrated by Claude Bernard's position with respect to the role of blood glucose concentration and metabolism, both in the normal and in the diabetic condition. In his days, more than a hundred years ago, blood sugar measurements were extremely complicated and time consuming, and were performed in the same experimental attitude as static glucose content of organ tissue, e.g. of the liver in animals was determined.

This may explain that, although arteries and veins were already known, and Claude Bernard was pointing vividly at the higher glucose content of hepatic veins relative to arterial blood, as strong evidence of the primary role of the liver in glucose production, changes in blood glucose concentrations under normal and pathological conditions escaped his and his contemporaries' attention. Hepatic glucose production, on the other hand, was not regarded in a static fashion. His drawing depicting glucogenesis under normal and diabetic conditions, was well aware of the differences between the minimal and the fully developed diabetic state, brought hepatic glucose production in relation to food intake and digestion, saw the increases and decreases in a complete dynamic rhythm, and took the glucosurea, resulting from excess glucose production overflowing the renal threshold, as indicator of the glucose movements in the body fluids (Fig. 1). This figure he published in 


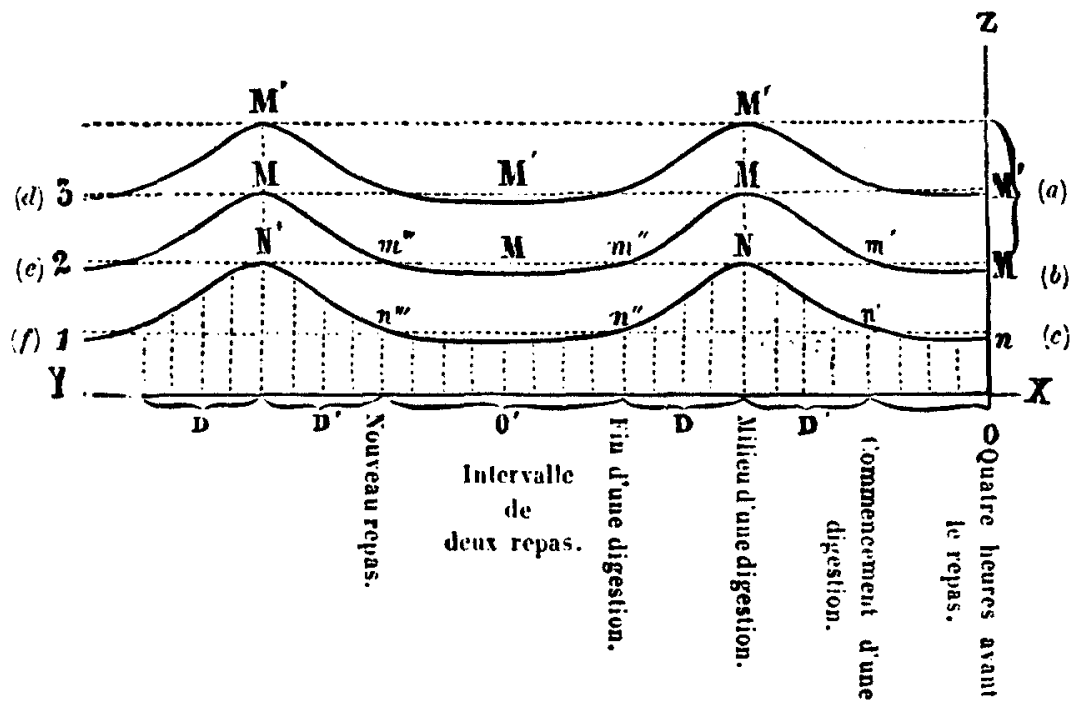

Fig. 5 . (a) Présence du sucre dans l'urine. (c) Ligne du minimum pliysiologiıue.

(b) Ligne du maximum de la produc- (a) Courbe du diabite continu. dans l'urine, majs le sucre appa-
rait dans tout le sang.
Fig. 1. The dynamic rhythms of changes of sugar in different body provinces as seen by Claude Bernard in 1855 , in relation to permanent and temporary diabetic conditions (from Claude Bernard, 1854/55)
1855 in his "Leçons de Physiologie Expérimentale Appliquée à la Médecine". It could be undoubtedly accepted for any modern textbook.

Moreover, 20 years later, shortly before his death in his "Leçons sur le diabète et la glycogenèse animale", he wrote this very modern, advanced and appropriately sounding statement which is not only valid to be presented to this international audience, but also could be taken as some kind of "motto" of this lecture:

Vous savez en effet que le sang, comme milieu intérieur dans lequel vivent tous les éléments anatomiques de l'organisme, présente et doit présenter normalement une composition à peu près constante. Parmi ses éléments de composition constante se trouve le sucre. Dès que cette substance y est surabondante, l'excès en est si sensible à l'organisme, que le filtre rénal l'élimine aussitòt; mais si la source hépatique continue à en produire plus que la dose normale, les tissus, malgré cette élimination incessante, sont toujours baignés par un sang trop sucré. Or ce contact peut amener en eux des troubles et des lésions matérielles, qui elles-mêmes peuvent constituer l'un des principaux dangers de l'hyperglycémie. Nous ne savons encore rien sur le mécanisme pathologique de l'action de cel excès de sucre dans le sang (from: Claude Bernard, Lecons sur le Diabète, 1877¹).

\footnotetext{
1 "You know that de facto the blood, as the "milieu intern" for all tissues of the organism, consists and should consist normally of a quite constant composition. Among those elements of constant composition sugar is found, too.

However, if its level exceeds a certain limit, the organism is sensitive to that excess, and therefore renal filter provides the elimination; however, if sugar continues to be overproduced (by the liver), in an excessive way, the tissues, in spite of continuous elimination, will be constantly "bathed" in a hyperglycaemic (blood) medium. (It easily could be) that this contact (between elevated glucose concentrations and tissues) might produce functional troubles and morphological lesions. That might represent one of the principal risks of hyperglycaemia per se. Up to now, we do not know anything regarding the pathogenetic action of sugar excess (elevation) in blood" (from Claude Bernard: Leçons sur le diabète, 1877).
}

This he wrote 10 years before von Mering and Minkowski demonstrated the presence of a blood sugar lowering antidiabetic substance in the pancreas, many years before the well-established and practiced insulin therapy did permit diabetic patients and doctors to experience the diabetic complications!

Hundred of years later, we still do not know exactly how hyperglycaemia effects the secondary complications of diabetes in certain tissues. But, eventually, we blame, too, the excessive glucose concentrations (or fluctuations) in blood for disturbing Claude Bernard's "milieu interieur" and to be causatively related somehow to the development of diabetic neuropathy, nephropathy and retinopathy, etc. Undoubtedly behind all of our efforts to renormalize diabetic hyperglycaemia is encased the tacit understanding that the uncontrolled excess of blood glucose concentrations is representing the "causa movens" ensued by all bad sequelae, and vice versa, that correction of that defect of the internal "milieu" readily will prevent, delay or improve, the microvascular lesions in the various pre-, prolatent or overt stages.

In the present "Claude Bernard Lecture 1985"I shall try to show the way from the dark past, when we were not aware of the significance of blood sugar elevations, to the present grey, where we demonstrate and know our failures with only temporary remedies, to the most probably, in our opinion, rosy future, where automated glucose determination is permitting constant and feedback-regulated control. 


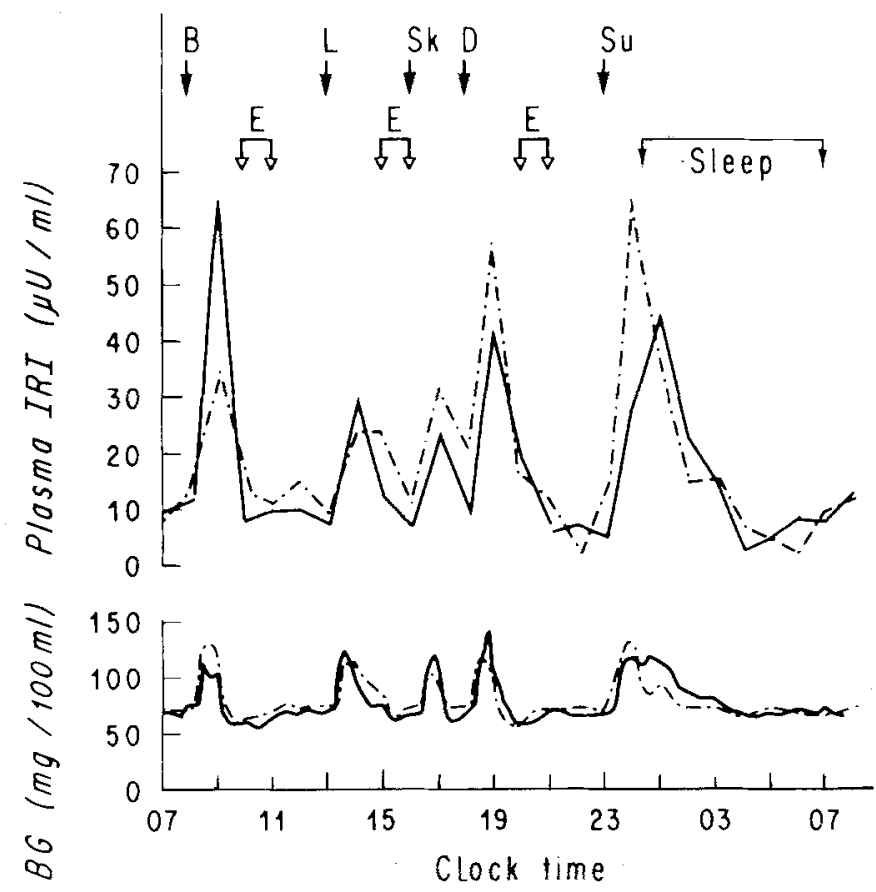

Fig. 2. Parallelism between blood sugar and plasma insulin concentrations in normal subjects (from [1])

\section{The dark past}

As it frequently was the case in medicine, analysis preceded therapy. In the sixties, continuous blood glucose monitoring was made available thanks to the pioneering work of Ferrari, Bonnafé, Weller and others, who combined the double lumen catheter, permitting extracorporeal heparinization, with the modified Technicon Autoanalyzer. This new technique was used extensively by physicians like Molnar and Service in the United States, Mirouze in France and Kruse-Jarres [1] in Germany, to demonstrate the true quality of blood glucose control, attained in the individual patient by conventional insulin therapy. The insight gained was terrifying, especially when comparing the completely unrelated widely fluctuating chaotic blood sugar and blood insulin levels over $24 \mathrm{~h}$ with the perfect and almost aesthetic parallelism between the two parameters in the metabolically healthy subject (Fig. 2).

In the diabetic patient, fluctuations of blood glucose levels were not only extremely high after subcutaneous injection of an intermediate insulin once daily, they also, as we soon discovered, could not be prevented by two injections, the combination of intermediate and regular insulins, or multiple injections of the regular preparation (Pfeiffer et al. 1972).

The obvious failure of also intensified conventional therapy - as we address that type of treatment today to assess normoglycaemia in Type 1 diabetes was the

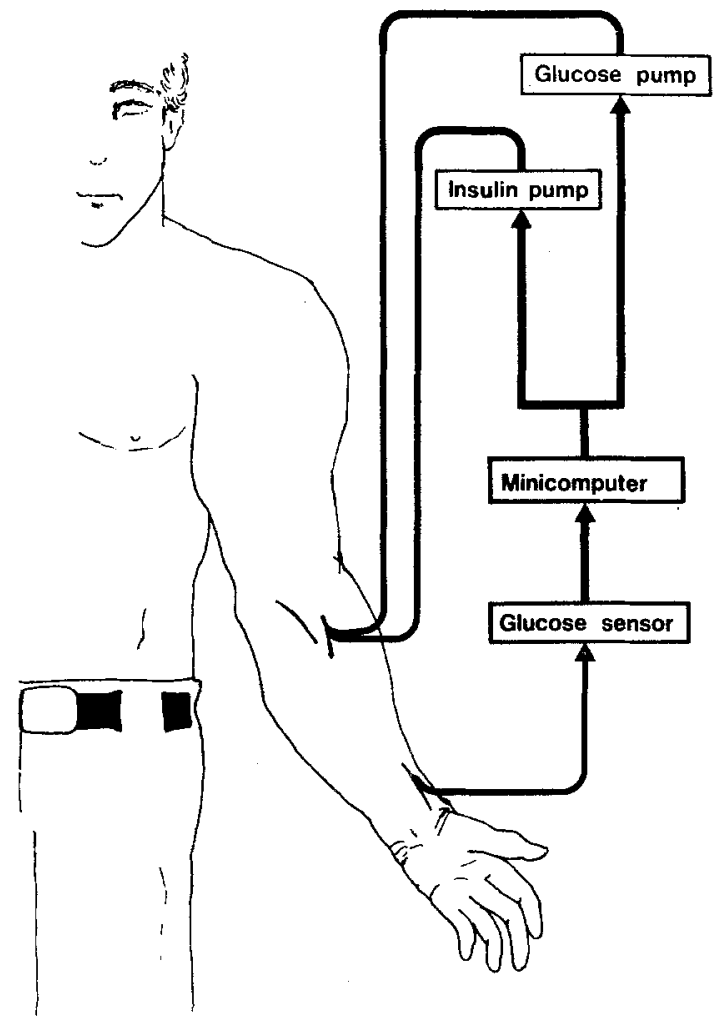

Fig. 3. The basic elements for a feedback regulation of blood sugar

last push into actively engaging ourselves in 1972 in the attempt at restoration of normal blood glucose levels via re-establishment of feedback control. That implied that glucose could be continuously determined in small quantities in peripheral venous blood, and insulin (and, if needed, glucose) should be pumped, too, in a peripheral vein. By means of a microcomputer (which became available just for the first time in recent years), calculating (on the basis of the continuously inflowing glucose concentrations) according to programmed algorithms the needed amounts of insulin on a minute per minute basis, the feedback between glucose and insulin should be re-established, i. e. the loop between substrate and regulator should be closed over the patient (Fig. 3).

So three parts of this extracorporally working "Artificial Endocrine Pancreas" (AEP) or "Beta-Cell" (Pfeiffer, Thum and Clemens $[3,4]$ ), correctly described already at that period as the "GCIIS" or "Glucose Controlled Insulin Infusion System": the sensor, the pump and the computer were, are, and most probably will be the irreplacable components of all similar devices; they were developed and presented also in 1974 by Mike Albisser, Bernard Leibel, and their associates in Toronto, and later in various laboratories, as in Sydney, Montpellier, Osaka, Erlangen, and Paris.

Undoubtedly, there had been already several attempts to achieve renormalization of blood glucose in diabetic patients by automated regulation of insulin before. One of the first certainly was Kadish who in 1964 
Table 1. Lag time and blood loss in continuous extracorporeal glucose measuring by electroenzymatic methods

\begin{tabular}{llcl}
\hline & Detection & $\begin{array}{l}\text { Lag time } \\
(\mathrm{min})\end{array}$ & $\begin{array}{l}\text { Blood loss } \\
(\mathrm{ml} / \mathrm{h})\end{array}$ \\
\hline Kadish et al. (1965) & $\mathrm{O}_{2}$ Electrode & 4 & 6 \\
Clemens et al. (1976) & $\mathrm{H}_{2} \mathrm{O}_{2}$ Electrode & 1.5 & 2 \\
Layne et al. (1976) & $\mathrm{O}_{2}$ Electrode & 6 & $1-3$ \\
Schindler et al. (1977) & $\mathrm{O}_{2}$ Electrode & 4 & - \\
Updike et al. (1979) & $\mathrm{O}_{2}$ Electrode & $<1$ & 6 \\
Abel et al. (1983) & $\mathrm{H}_{2} \mathrm{O}_{2}$ Electrode & 1.5 & 5 \\
\hline
\end{tabular}

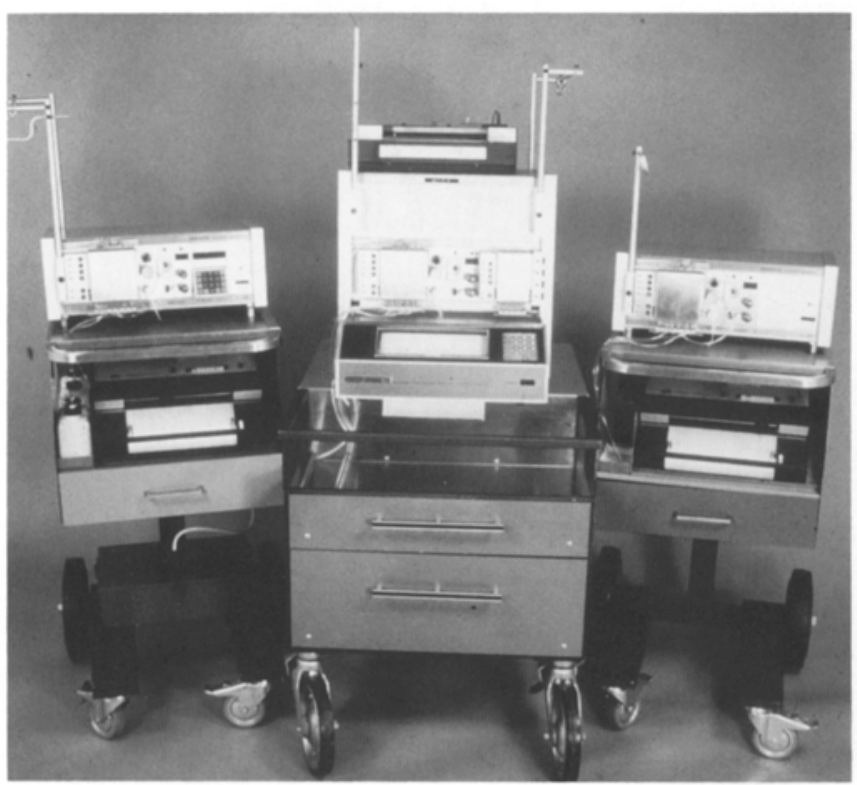

Fig.4. Our artificial endocrine pancreas (Ulm-Elkhart Version) and two simplified versions as glucose controller and glucose monitor

already wrote that "this system is capable of continuous blood sugar monitoring and release of insulin, whenever the blood sugar level exceeds $150 \mathrm{mg} \%$ and release of glucagon, whenever the recorded sugar curve drops to $50 \mathrm{mg} \%$ or lower" (Kadish, 1964). However, this "OnOff-System" did not reinstitute normoglycaemia.

Happily enough, Kadish's papers were published exclusively in Medical Engineering Journals and escaped ours and the attention of the other medical investigators. The simple explanation he gave recently to me after having read one of our review papers in which we quoted his first attempts but did not include his later efforts, was: His papers between 1964 and 1977 were not accepted by the medical journals approached (Kadish, 1985; personal communication).

I said "happily", since, if we had known of the failure of an experienced bioengineer, most probably we, as medical people, had not attempted to step into that bioengineering game reserve. However, we did and soon we were confronted with the problem that the time lag between withdrawal of blood, blood sugar determination, communication to the ordinating computer, activation of the insulin pump, lasted about 6-9 min and simply was too long for permitting close feedback regulation. The glucose to be regulated escaped its regulator.

Eventually, the situation was changed to the better when A.H.Clemens, a German engineer, working with Miles/Ames, at Elkhart, Ind., joined our group, and introduced the then novel electroenzymatic technique, evaluating the conversion of glucose to peroxide and gluconic acid by means of the "Yellow-Springs-Membrane", utilizing glucose oxidase for blood glucose conversion.

The lag time now was in the range of $1.5-1 \mathrm{~min}$ (Table 1). Clemens also incorporated all four parts of the bulky machinery which was representing until then our AEP or GCIIS into one apparatus, which afterwards became the first of the so-called commercially available "Biostator" series. Two modified and simplified versions exist as "glucose controller" as well as glucose "monitor" (Fig.4). With those apparatuses we are leaving the dark past and enter the still grey present of a variety of insulin infusion systems of different quality for blood sugar control.

\section{The grey present}

The development of algorithms for the mathematical handling of the AEP had shown the importance of insulin infusion kinetics on actual blood glucose control. The attempt to simply relate the insulin delivery to the actual blood glucose value, the proportional control, [irrespective of which type of insulin profile was selected (tangens hyperbolicus, linear, square, doublesquare)] was just sufficient for the static control under fasting conditions. Reestablishment of normoglycaemia following food intake was not obtained until difference or differential factors were introduced, anticipating the blood sugar concentrations from the evaluations of the last series of determinations. Only the combination of the two control modes produced not only control of the basal glucose in the fasting state, but also by calculating the insulin infusion rates in response to changing levels of glucose following food absorption (Fig. 5). When glucose rose steeply, more insulin had to be infused than was expected from the static control. As glucose fell, less insulin had to be given to avoid hypoglycaemia. The dextrose infusion part of the AEP, on the other hand, was always regulated solely by the proportional control.

Kerner, Clemens and others in our laboratory also were engaging themselves with the question of calculating the insulin requirement for conventional therapy on the basis of insulin delivery demanded automatically by the AEP. The algorithms for providing sufficient insulin supply during the first dynamic phase usually were demanding insulin quantities 10 to $20 \%$ higher than needed in subcutaneous therapy (Kerner et al. 1976, Kerner et al. 1979). A certain practical information as to the insulin requirement in the individual patient, inde- 
pendent from any immunological or non-immunological insulin resistance, will be provided, has also been found by others (Bayer et al. 1979; Lambert et al. 1979; Christiansen et al. 1979). On the other hand the quality of control as obtained by the "closed loop system" in relation to the conventional "open loop application" does not permit any direct comparison.

The finer tuning of blood sugar control also went hand in hand with a number of practical information: The normal situation when already at the early beginning of food intake, insulin secretion starts because of some pre-information by the neuro-intestinal system, cannot be simulated by the automatically working device. As shown by Kreagen et al. (1981) and Kerner et al. (1984) insulin infusion profiles from the AEP, advanced by 15 to $20 \mathrm{~min}$, effectively improved the postprandial blood glucose control (Fig.6).

Furthermore, a circadian variation in insulin requirement was established during $24 \mathrm{~h}$ (Kerner et al. 1982). Utilization of breakfast and early meals required an average of $1 / 3$ more insulin since consumption of the same amount of carbohydrates at noon and in the evening (Fig. 7). This observation might be perhaps connected with the so-called dawn-phenomenon, that means higher blood glucose and insulin concentrations in the early morning hours and during the first part of the night (Clark et al. 1980; Kerner et al. 1984). In our hands, under glucose controlled insulin infusion, an increase of the insulin requirement from $8-50 \mathrm{mU} / \mathrm{min}$ was observed between 03.00 and 04.00 hours in the majority of the patients examined. If the insulin was not

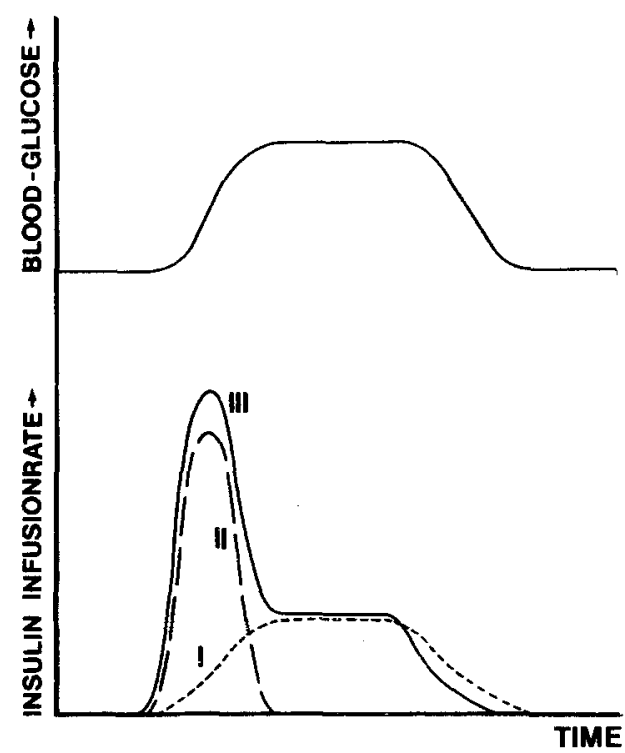

Fig.5. The three principal operational modes for insulin infusion. I static control mode; II dynamic control mode; III static + dynamic control mode (from [38])
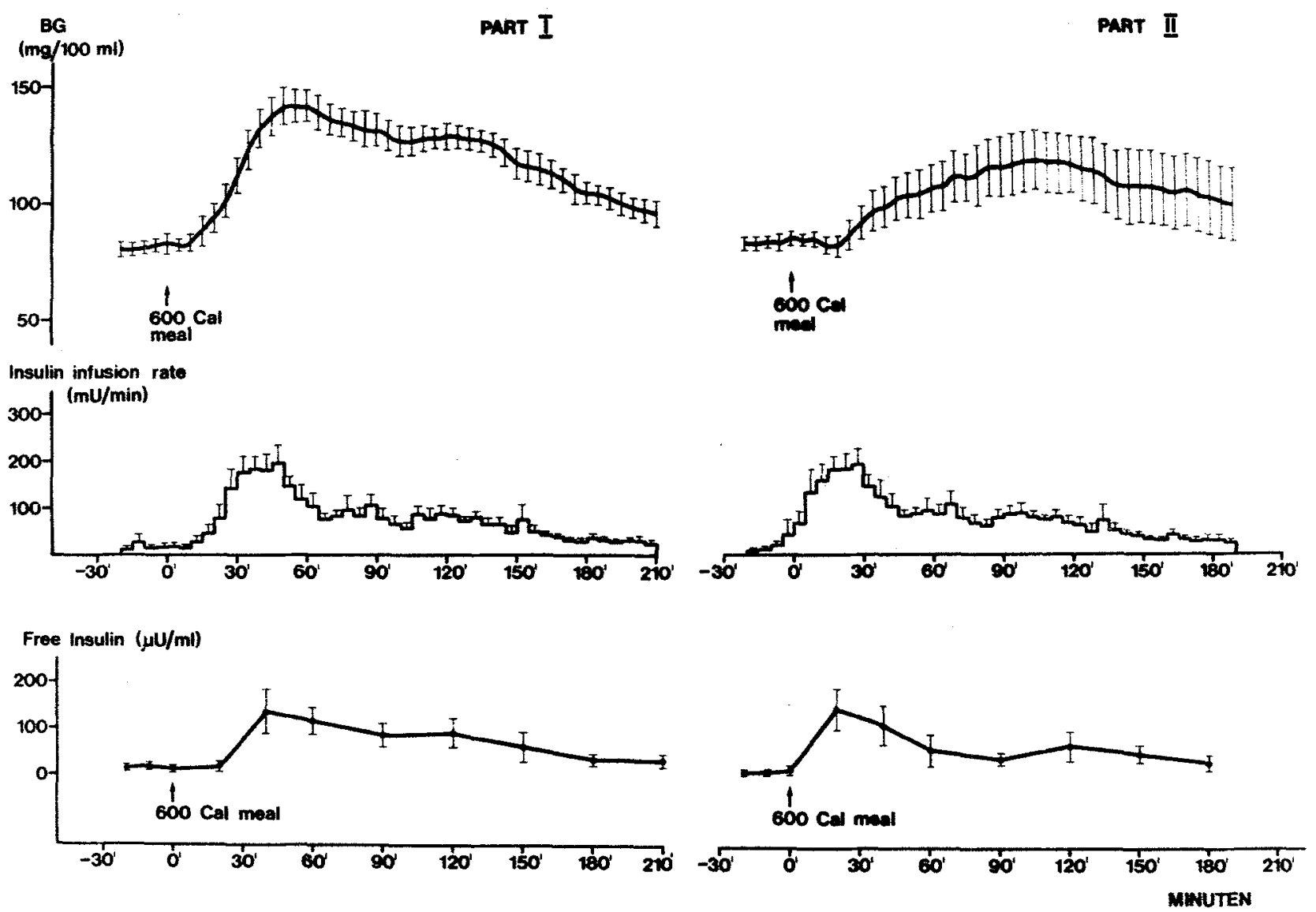

Fig. 6. Improvement of postprandial blood sugar levels by use of insulin infusion profiles from the artificial endocrine pancreas, advanced by 15 to 20 min to a meal (from: Kerner et al. 1984) 

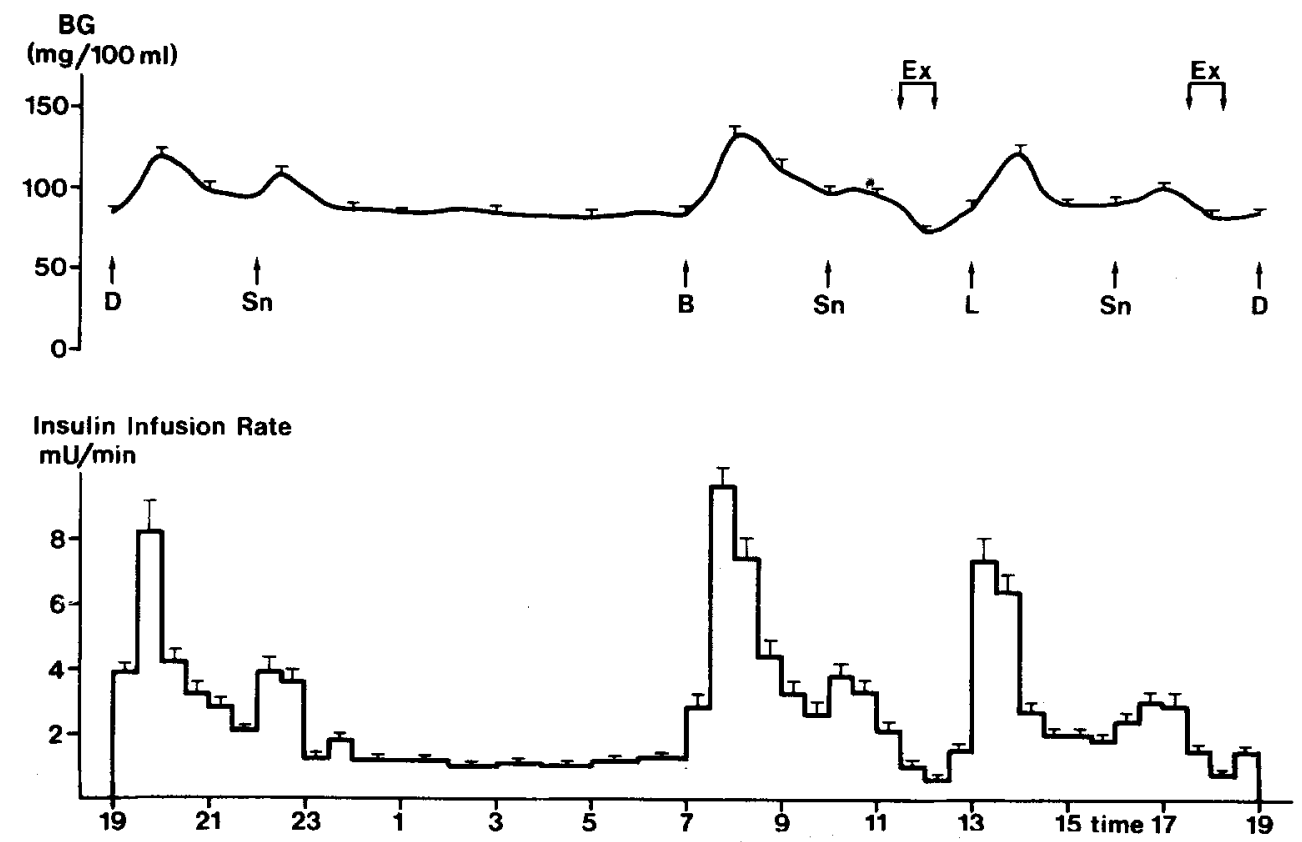

Fig.7. Variation in insulin requirement during $24 \mathrm{~h}: 1 / 3$ more insulin is required for the same amount of carbohydrates in the morning (from: Kerner et al. 1982)

regulated and only the constantly programmed insulin infusion was applied, remarkable increases in the blood glucose concentrations were seen. This already resulted in practical suggestions as to the programming of the open loop portable insulin infusion pumps.

The better tuning of glucose regulation by automatic means also permitted to answer the classical question of whether complete blood glucose normalization is accompanied by correction of the abnormalities in lipid and amino acid metabolism as well as in the secretion of the insulin antagonistic hormones, in other words, of whether or not these derangements are primarily related to the etiopathogenesis of diabetes or whether they are purely secondary phenomena. If the latter were true, then reinstitution of normoglycaemia should not only correct metabolic and endocrine disturbances but also prevent, reverse, or at least, improve the diabetic microvascular complications.

As for glucose, in the fasting state as well as after food intake blood glucose levels in any Type 1 diabetic patient are completely renormalized (Meissner et al. 1975; Marliss et al. 1977). A complete parallelism between blood glucose values and insulin secretion rates were established and also (not shown) to insulin in peripheral blood. These euglycaemias also had been preserved on the AEP under exercise conditions without requiring any additional control parameters (Schock et al. 1980).

However, the free or not antibody-bound insulin values under feedback control effected by the AEP system, significantly exceeded the values measured in the normal subjects in both the fasting and the postprandial state (Hanna et al. 1980; Horwitz et al. 1980; Voss et al. 1982; Kerner et al. 1984). Identical observations were made following successful pancreas transplantation (Pozza et al. 1985).
In general, this relative hyperinsulinism is ascribed to the peripheral route of insulin administration, and the lack of primary insulin degradation in the liver tissues. On the other hand, the Toronto group repeatedly demonstrated identical insulin requirements demanded by the AEP irrespective of portal or peripheral route of insulin supply (Botz et al. 1976); and Christiansen and associates (1981) following treatment with the AEP measured normal peripheral insulin concentrations. As far as glucagon levels were concerned, the generally observed increased levels in Type 1 diabetic patients on conventional therapy were rapidly brought back to normal and remained normal also after stimulations with arginine or exercise (Schock et al. 1978; Schock et al. 1981; Kerner 1984).

However, 3 days of treatment were not sufficient to renormalize the generally elevated growth hormone concentrations. In our hands bicycle ergometer tests ( $75 \mathrm{~W}$ for $45 \mathrm{~min}$ as an exercise) as well as arginine infusions revealed the same increases in growth hormone levels in diabetic patients as under conventional and under AEP treatment. The significance of these studies should not be overemphasized. Most probably, the time period in which normalization by feedback regulated automated blood glucose control was achieved, was not sufficiently long enough for complete restoration of the normal situation of all parameters concerned. The same was true when some intermediary metabolites, as the branch-chained amino-acids were measured.

In conclusion, renormalization of the disturbed blood sugar regulation is possible and feasible in any insulin-dependent diabetic patient by means of the AEP, irrespective of how long the derangement persisted immediately after feedback regulation between glucose levels and insulin delivery was re-established. In consequence of restoration of normoglycaemia, even in 
the short time experiment most of the deranged hormonal and metabolic parameters were returning to normal, too. The exceptions were the growth hormone and certain metabolites as branch-chained aminoacids, the beta-hydroxy-butyrate, lactate and pyruvate. Most probably prolongations of the periods of normoglycaemia shall also correct these parameters to normal values.

While the capacity of the system to restore normality of most secondary parameters of the hormonal and the metabolic system obviously required a very fine, if not ultrafine, tuning (obviously only provided by prolonged periods of complete restoration of the normal euglycaemic situation) also the most extreme clinical situations of hyper- and hypoglycaemia were readily brought under control by the system, as shown for insulin in diabetic ketoacidosis and for glucose delivery in severe malignant insulinoma.

The summary of the clinical applications is given in Table 2, while we have to refrain from discussion of all other applications of the AEP to clinical and pathophysiological problems for the sake of dealing with the main subject of this lecture, i. e. the heading of this section, the grey present. Why do we call this period "grey"? It is well understood that the problem of the present AEP is not any lack in capacity but that it is still a bedside apparatus which cannot be worn by the patient, and is requiring, because of the necessity of continuous blood sampling for measurements of glucose in diluted blood in flow analysis, while the blood afterwards has to be discarded, at least $30 \mathrm{ml} / 24 \mathrm{~h}$. Despite the fact that already in the first paper we foresaw the smaller portable instrument, if necessary only of temporary use, not much progress was made since then. We still lack a reliable working implantable glucose sensor.

The explanation is simple: the cessation of the activity of the electrochemical sensor after an unpredictable number of hours required the change of the membrane every $24 \mathrm{~h}$. The explanation is given by a scanning elec-

Table 2. Some applications of the artificial endocrine pancreas in clinical therapy (from: Pfeiffer 1976)

\footnotetext{
- Diabetic coma

- Surgery in diabetic patients

- Total pancreatectomy

- Delivery (diabetic mothers)

- Organic hyperinsulinism

- Haemodialysis in diabetic patients

- Induction of the remission phase (honeymoon period)

Evaluation of insulin doses for subcutaneous therapy
}

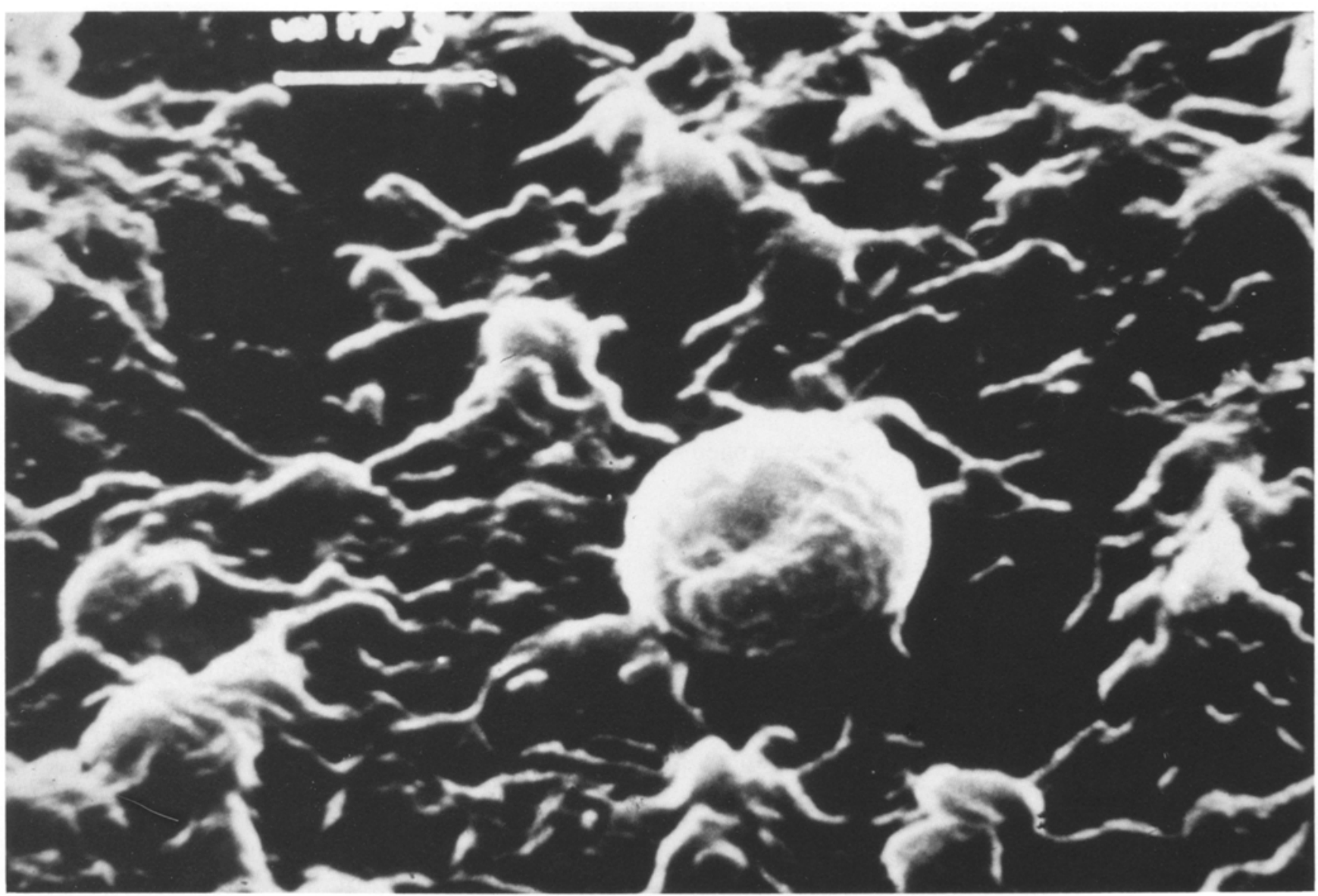

Fig. 8. Reaction of the body against foreign material of the glucose sensor membrane shown by scanning electronmicroscopy (from: Clemens et al. 1976) 
Table 3. The development of different continuous insulin infusion systems [from Mirouze J (1983) Diabetologia 25: 212]

\section{Closed-loop system: artificial endocrine pancreas \\ 1974: Albisser et al. \\ 1974: Pfeiffer et al. \\ 1975: Mirouze et al. \\ Open-loop system: Pumps \\ Short-term: venous continuous insulin delivery \\ 1974: Slama et al., Type 1 diabetes \\ 1977: Genuth and Martin, Type 2 diabetes \\ 1976: Deckert et al., Brittle diabetes \\ 1976: Hepp et al., Type 1 diabetes}

Long-term: subcutaneous, venous or peritoneal routes of continuous insulin delivery

1978: Pickup et al., Type 1 diabetes

1979: Irsigler et al., Type 1 diabetes

1979: Mirouze et al., Brittle diabetes

Table 4. Frequency of complications of insulin pump therapy

Unconscious- Ketoacidosis Infections
ness
due to
hypoglycaemia

\begin{tabular}{|c|c|c|c|}
\hline \multicolumn{4}{|l|}{ All patients } \\
\hline Absolute incidence & $31 / 208$ & $47 / 212$ & $50 / 203$ \\
\hline \multicolumn{4}{|l|}{ Incidence $/ 100$ days } \\
\hline Mean \pm SEM & $0.11 \pm 0.03$ & $0.18 \pm 0.04$ & $0.27 \pm 0.05$ \\
\hline Range & $\begin{array}{ll}0 & -3.9\end{array}$ & $0-4.5$ & $0-5.0$ \\
\hline$n(\mathrm{f}>1)^{\mathrm{b}}$ & 6 & 13 & 14 \\
\hline
\end{tabular}

a Number of patients affected / number of patients reported

b $n$ ( $f>1$ ) Number of patients in whom incidence exceeded $1 / 100$ days

tromicroscopical picture of the membrane: precipitation of blood cells, thrombocytes, fibrin, leucocytes and other materials on the membrane as part of the defence reactions of the body against foreign material prevented further sensor activity (Fig. 8). By that picture we were mentally blocked to such an extent that we stopped all further efforts. It was only the group of Shichiri from Osaka, who went on and ahead, undisturbed by all theoretical reflections, converting the AEP technology as good as possible into a portable feedback controlled system.

However, as everybody knows, one was not willing to wait until an implantable glucose sensor was created. Various groups used the profile elaborated by the AEP to start with the so-called "pre-programmed" insulin infusions via portable pumps. In other words, one was satisfied with portable pumps delivering continuously a daily dose of 1-2 U of insulin/h, i. e. $24 \mathrm{U} /$ day, supporting this basal insulin infusion by additional insulin supply, the so-called boluses, at the periods of meal intake for food utilization. In quite a strong competition, as to time, the various modifications of insulin supply were suggested, as Mirouze showed it in his Claude Bernard Lecture in 1983 (Table 3), and today more than 30 various types of pumps are offered to the medical and nonmedical public.
Frequent self-determinations of blood glucose by the patient are required. The patient is acting as the sensor, after being introduced to the technique, as his own computer and calculator, and, eventually, at meal time, as his own pump performer.

What were the results? Up to this congress disappointing: the continuously performed insulin infusions by the open-loop systems, and effected by portable pumps, over 1- and 2-year periods did not favourable influence the already present also not much progressed retinal micropathology as has been found more or less uniformly by the Steno Hospital in Denmark as well as established by the Kroc Foundation Study in the United States and in Great Britain.

Only at this congress were there additional findings by Norwegian authors and again by the Steno Group, that when continuing the infusions, no further microaneurysms were formed.

Of course, various explanations are possible to understand that programmed insulin delivery is not as competent in optimizing insulin application as achieved by feedback-regulation, since a number of remarkable oscillations of the blood glucose concentrations certainly cannot be prevented. Of course, hyperglycaemic reactions are correctly observed only when continuous blood glucose monitoring is performed, and daily blood glucose profiles, as obtained by the feedback controlled AEP, are compared with the ones seen under programmed insulin pump treatment.

It is also not much help to be expected from the combinations of insulin infusion profiles obtained by the AEP, and the transfer of these profiles by means of magnetotapes the following day to the same patients, without automatic correction of the insulin delivery by continuously measured blood glucose concentrations. Uncontrolled hyperglycaemic reactions are registered during the nocturnal periods despite continuously ongoing insulin supply (Pfeiffer and Kerner 1979; Kohlendorf et al. 1979; Staflinic et al. 1979).

This implies that constant adaptation of insulin delivery to the changing pattern of the blood glucose, and vice versa, changing in the same individual under identical conditions, as one of the features of normal biology, is necessary for providing the perfect feedback control.

So it easily could be that the quality of control obtained by the pumps was attaining a minor degree of renormalization. The other possibility, of course, were the time period when the insulin infusion treatment was started. Strict control perhaps is required much earlier in the life of the diabetic patient.

The other problem consists of the side reactions. Out of about 200 diabetic patients, observed by $20 \mathrm{Eu}-$ ropean centers collaborating in the Study Group on "Artificial Insulin Delivery Systems and Pancreas and Islet Transplantation" of the EASD, about $10 \%$ of the pump treated patients suffered from hypoglycaemic reactions, inducing unconsciousness (Table 4). 


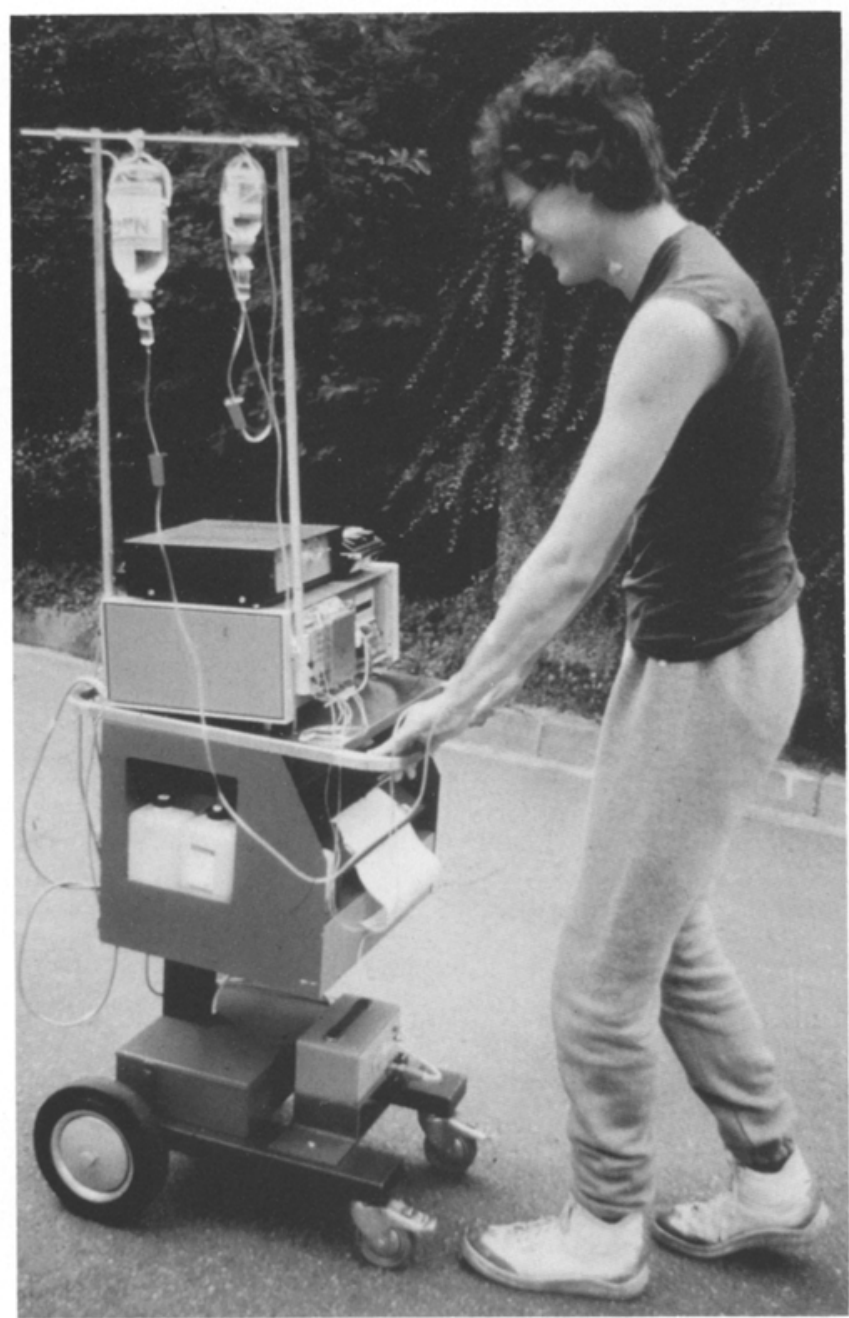

Fig.9. The mobile version of a continuous glucose sensor (taken from the Ulm artificial pancreas)

To obtain unbiased information, we constructed a mobile glucose sensor; for that purpose, the glucose monitor part of the AEP was converted by our engineer in such a way that the energy production was provided by batteries and accumulators, i.e. independence from the usual current was obtained (Fig.9). While continuous insulin infusion was effected by portable pumps, the glucose measurements were continuously performed likewise, i.e. the patients were moving freely in the hospital precinct (Arias et al. 1984). Hypoglycaemic periods with blood sugar values below $50 \mathrm{mg} \%$ were measured up for to $7 \mathrm{~h}$ duration within the $24 \mathrm{~h}$ of the day in several patients. These hypoglycaemic periods were clinically not always evident.

In summary, the incidence of hypoglycaemic episodes in diabetic patients following CSII and ICT, assessed by ambulatory $24 \mathrm{~h}$ continuous blood glucose monitoring, measured glucose values below $50 \mathrm{mg} \%$ in 9 out of 10 under CSII, and 5 out of 9 patients under ICT. In both groups hypoglycaemia was most frequent at noon (Fig.10), and was related to elevated pre- and postprandial free insulin. Patients became aware of hypoglycaemia only in 6 out of 23 (CSII) and 6 out of 8 episodes (ICT). Some of these episodes lasted up to $422 \mathrm{~min}$ !

Despite of similar quality of previous blood glucose control $\left(\mathrm{HbA}_{1} 8.0+0.05 \% \mathrm{CSII}\right.$ versus $8.0+0.3 \%$ ICT), blood sugar profiles showed better regulation under CSII treatment, i.e. mean blood glucose amounted to $99.6+10$ versus $133.1+7.4 \mathrm{mg} \%$ (i.e. M-value of $12.3+3.5$ versus $26.2+4.1$ ) or a Mage of $71.9+8.7$ versus more than $32.9+14.2 \mathrm{mg} \%$ (CSII versus ICT).

To make a long story short, conventional home blood glucose monitoring is unable to detect these extended periods of hypoglycaemia, reassessing the traditional experience of closed correlation between agressive insulin therapy and enhanced hypoglycaemic risk.

Summing up, we can offer today continuous insulin infusion therapy to the patient as alternative to conventional treatment by injections; we can aim, and sometimes may obtain, nearly normal blood glucose concentrations, and this type of therapy may compete with the intensified conventional treatment with the ICT of insulin by multiple injections, combining short and long acting insulin preparations. This new type of agressive insulin therapy is running higher risks than the conventional treatment with insulin injection. Hypoglycaemias are representing only one of those risks. The complications are not overcome yet, and better permanent control only can be achieved after a permanently working, implantable glucose sensor has been developed. On the other hand, we also have registered positive results as further improvements in diabetic neuropathy and prevention of malformations, miscarriages and early death of children of diabetic mothers are concerned, by the presently used continuous insulin infusion renouncing blood glucose control.

\section{The rosy future}

With that we are entering the last part of this lecture devoted to the development of the implantable AEP and, as we hope, starting the rosy future, that will be discussed in the remainder of this Lecture.

Here the first problem consists of the implantable glucose sensor. Two problems had to be overcome. On the one hand, neutralization of the sensor takes place at the result of the efforts of the body to eliminate foreign materials present in the peripheral circulation (precipitation of fibrin, platelets, leucocytes, formation of connective tissues, etc. ...), as we have seen. On the other hand, the glucose measurement has to be improved in such a fashion that stability is provided.

For glucose measurements electrochemical sensors were used preferentially after the optical methods had not succeeded until now. From the electroenzymatic method down to the "Chemfets" = "Chemically Sensitive Field Effect Transistors", everything was tried. 


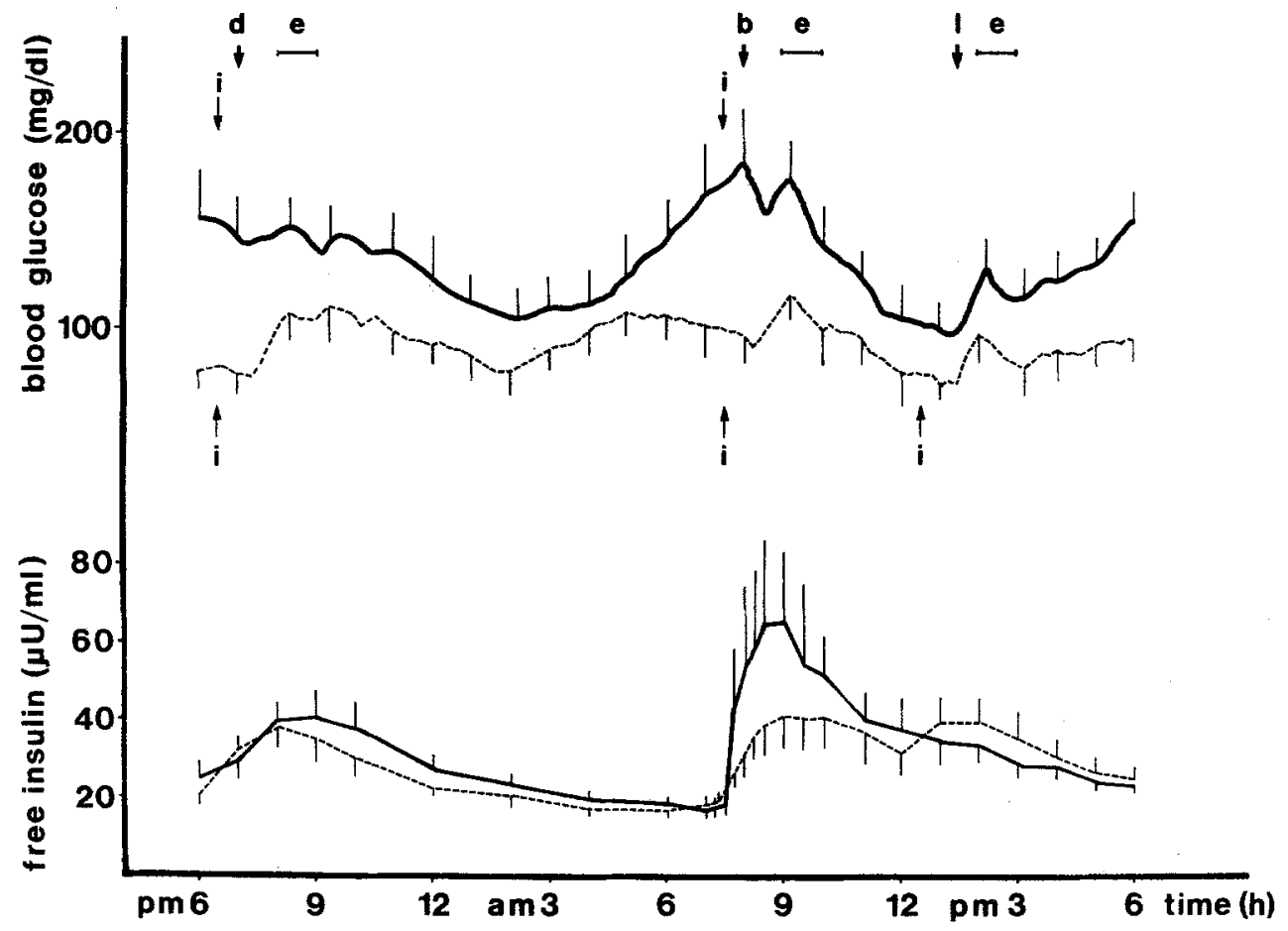

Fig. 10. Blood glucose levels and free insulin levels following CSII (...) and ICT (-) (from: Arias et al. 1985)

\section{Ag / Pt electrode (polarization voltage $0,7 \mathrm{~V}$ )}

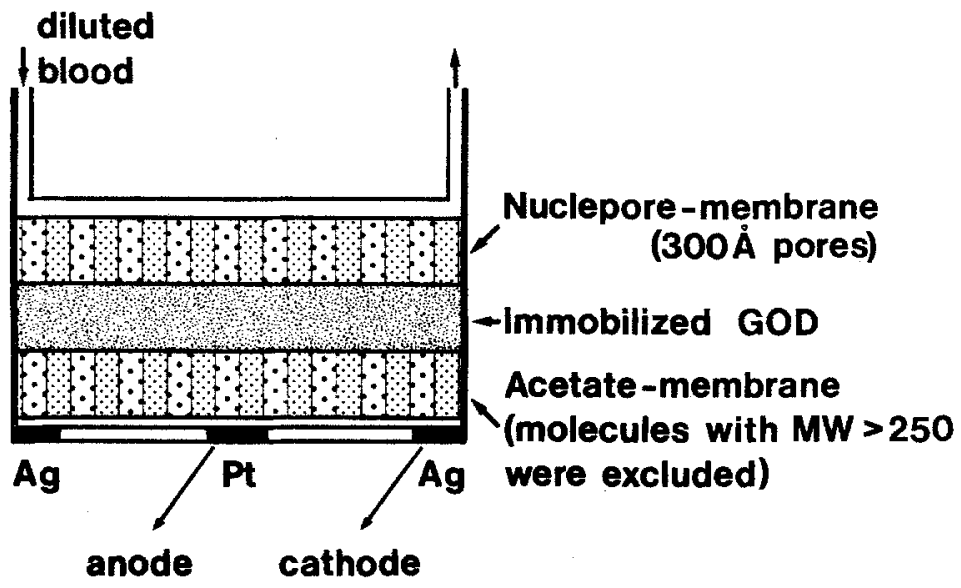

Fig. 11. The glucose sensor used in the artificial endocrine pancreas (from: Clemens et al. 1977)
However, after quite some exploration we returned to the electroenzymatic, electrochemical technique which we already had used in the first Ulm-Elkhart version of the AEP, the "Biostator" (Fig.11), similar as Fischer and Shichiri had adopted in their attempts at glucose determinations in subcutaneous tissues. This method always is based on an immobilized glucose oxidase (GOD), combined with amperometric detection of either peroxide, oxygen, changes in the $\mathrm{pH}$, or a number of other variations of indicator techniques.

Glucose $+\mathrm{O}_{2} \rightarrow$ gluconic acid $+\mathrm{H}_{2} \mathrm{O}_{2}$

The important parts are the substrate, the immobilized enzyme, converting the substrate to products and reactants, and the detector. In the original work of Clark and Lyons, Hicks and Updike, a traditional cation-selective glass electrode was coated with the enzyme, and some polymerized acrylamide gel matrix was used for coverage. In the meantime, PVC and polyuretan based matrices more or less have taken over. If they have different selective binding sites, lipophilic and lipophobe capacities for separation, these were preferential.

Although some of these glucose electrodes are already built in for flow-through determination, and commercially available in some laboratory instruments (Yellow Springs Industr., Model 23, Solea Tacussel, Model ENSL1, etc.), for the work with the implantable sensors, you still have to construct your own sensor.

By doing so, you are entering the fascinating field of Analytical Chemistry represented by the ion-selective electrodes, as vital part of modern electrochemical sensors.

The whole field is not entirely new. It is based on very old recognition of physical chemistry, i.e. that a 
chemical reaction is generating an electrical potential, measured in relation to the so-called inert reference electrode, also in contact with the sample. The trick consists of the fact that you have to find the right ion selective electrode, and by saying ion I understand that also anions can be measured that way, and to separate the substrate from the product. The advantage consists of the fact that undiluted samples can be evaluated and so not blood had to be withdrawn. In case of the enzyme electrodes, the question is represented by the big question mark, whether or not these electrodes are continuously to be reusable.

It is not generally known, that the so-called ion selective electrodes were already used in clinical chemistry on various occasions. One of the first examples was the glass electrode which founded the basis of a simple $\mathrm{pH}$ meter, developed and sold by Beckman. One of the more modern developments appeared at the end of the 1960 s, and this was the potassium electrode using valinomycin as the so-called neutral carrier. Flame photometry today practically can completely be substituted. The first so-called enzyme electrode did not appear before 1975. It was designed for urea measurements by Cammann in Ulm in the same year. At the same period the first application of the oxidase reaction was evaluating diluted blood for glucose measurements and this was incorporated into our AEP here in Ulm by our associate Clemens.

The electric energy generated by the chemical reaction with the specific selected anion can be measured in two ways, either by potentiometric means of by amperometry. In the first technique a membrane of sensing surface acts as a battery which generates the potential, proportional to the logarithms of the analyte concentration, the so-called activity. This is the type which was followed, as far as glucose is concerned, for years by Siemens and by Soeldner in the United States.

The other one is the amperometric electrode sensor. Here, a potential is applied between the reference electrode. The potential generated encourages the electron transfer resulting from the chemical reaction and causes a current flow proportional to the concentration of the analyte. The first one was the polarographic sensor for the measurement of the oxygen.

Because of the sensitivity needed in our case and for our electrode, which we had used already in these early years, we preferred the amperometric technique (Clemens et al. 1977; Pfeiffer et al. 1976), also in the implantable electrode for measuring interstitial or tissue glucose. A potential of $700 \mathrm{mV}$ is applied between the silver and the platin electrode, and the peroxide produced by the GOD-reaction is oxidized and measured in $\mathrm{nA}$. The $10-100 \mathrm{nA}$ measured are proportional to the glucose content of the solution, in the tissue interstitial fluid the presence of sufficient oxygen provided. After overcoming the temperature and pressure, out of the various variations of shapes of electrodes used for electrochemical sensing, we selected the following types

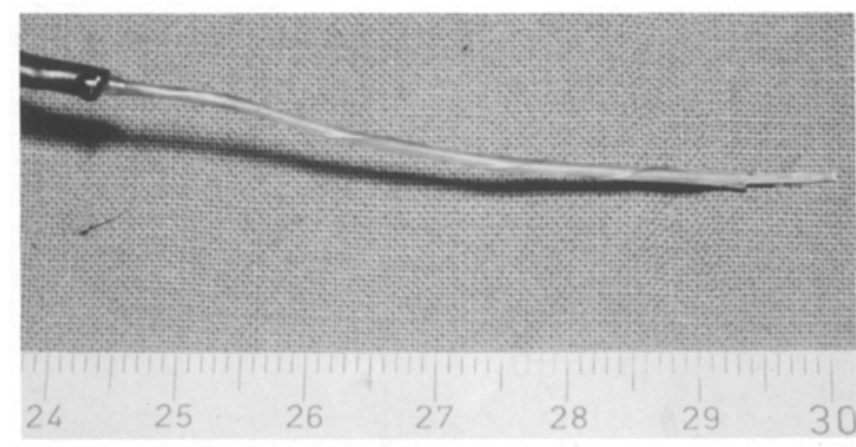

Fig. 12. The "new" glucose sensor

(Fig. 12). The electrodes were covered with silicon, various polymers, and tested for permeability of oxygen and glucose, for separation and for oxidase immobilization. Afterwards, in vitro and in vivo tests were performed.

Out of the many tests and many materials tested by our Dr.Kerner and Mr.Zier emerged a few constructions, suited for animal experimentation. The results obtained until now will be shown to you in the spirit of Claude Bernard, i.e. how he did in his lectures when presenting and discussing the results directly coming out of the laboratory, with his students.

Considering always the three problems of continuous glucose monitoring in circulation and in tissues stability (temperature, drift etc.), specificity, and biocompatibility, the electrode was put in a glucose containing fluid or diluted blood, conventional glucose measurement was likewise performed for control, and perhaps calibration, and then the experiment was continued for hours, days, weeks and months.

In contrast to the beliefs of our physico-chemical advisors, who were predicting electrode intoxication by electrons, and rapid decrease in capacity of glucose sensing, with the right mixture after some experimentation in the in vitro tests no drift was seen, and even after two weeks of continuous measurement increases in the glucose were readily registered in the long-term experiment as well as over the following weeks and months (Fig.13). The same holds true for rapid changes of blood glucose concentration in the medium.

The glucose sensor was placed subcutaneously in rats and the glucose content in the circulating blood was continuously monitored likewise with the miniaturized version of our "Biostator Endocrine Pancreas". When glucose was injected for increasing blood sugar concentrations, or on the contrary, insulin was given for producing hypoglycaemic reactions, a delay in the interstitial glucose concentration was seen as far as comparison with blood sugar changes were concerned.

In the other animal, the sheep, again, when comparing continuously blood sugar levels in the circulation and in the subcutaneous tissue, no drift was seen after the primary adjusting period. Again, when glucose was rapidly elevated by intravenous glucose injection a 


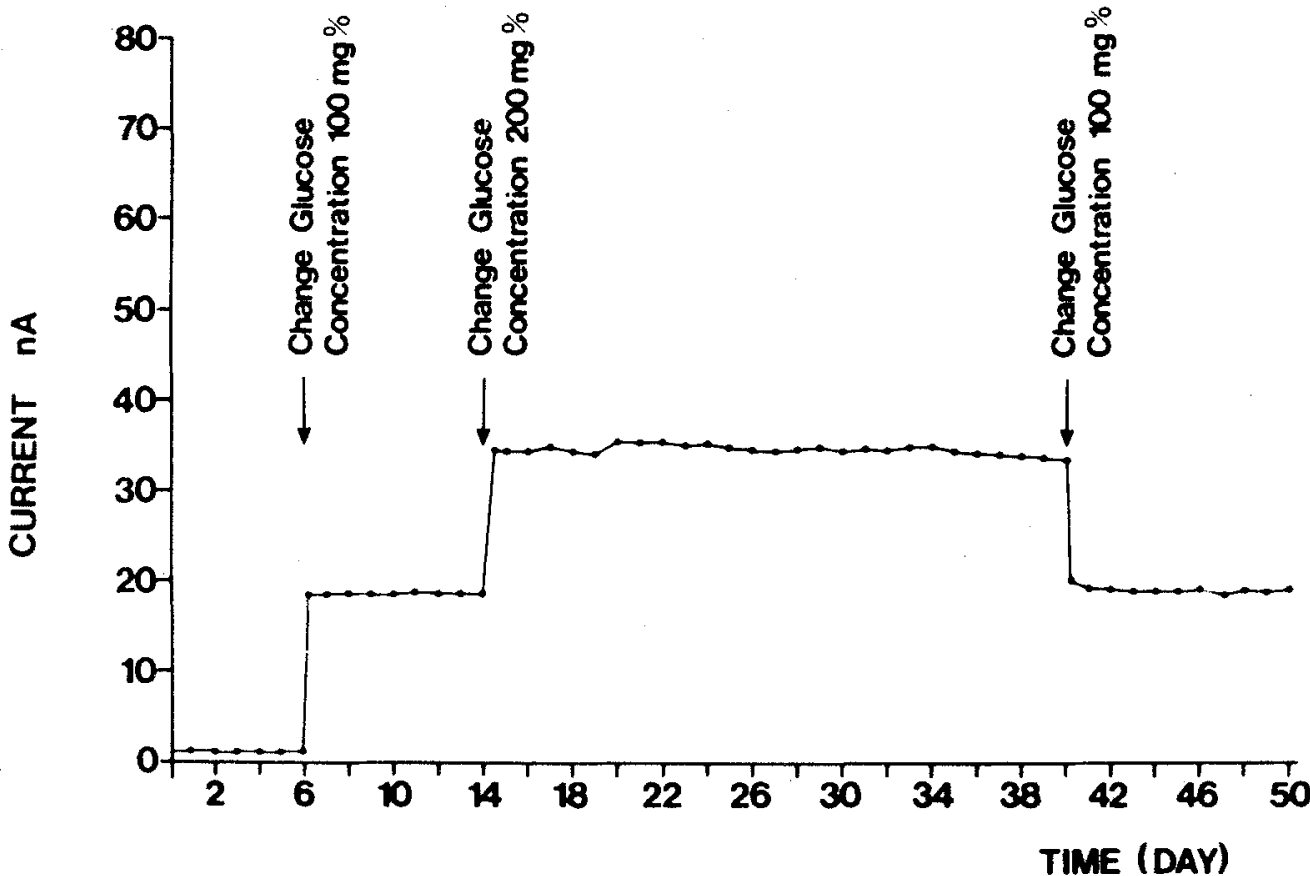

Fig. 13. Long-term testing of the "new" glucose sensor in vitro: glucose concentrations were stepwise changed

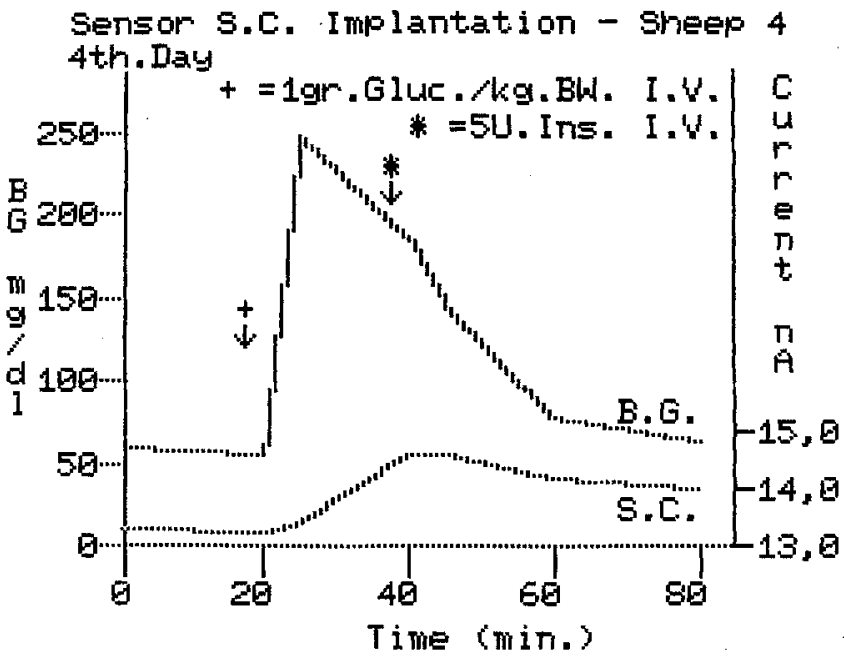

Fig. 14. The glucose sensor implanted s.c. in a sheep: comparison of blood sugar concentrations and glucose sensor output following an IVGTT (left ordinate: blood sugar concentrations, right ordinate: sensor output)

clear-cut delay between 5 and $15 \mathrm{~min}$, more often 10-15 min between the maximum increases, was registered, irrespective of the day of experimentation (Fig. 14).

I should like to draw your attention to the fact that the tissue glucose content we are not indicating as $\mathrm{mg} \%$, i. e. not evaluating the value measured in the fluid for some kind of calibration. We rather prefer to plot directly the electric energy in $\mathrm{nA}$, since the measurement of the current is reflecting in the present moment the actual situation, and identification of that electric current with the glucose concentration, measured in vitro, seems not justified, until direct glucose extraction out of the tissues has been performed in any individual case.
Also in the rabbit, the third animal in which the same experiment with the same experimental protocol was performed, the delays in the increase in the glucose concentrations behind the changes in blood sugar per se were observed, too. In the respective Figure 15 the electric current, ensured in the subcutaneous tissue is given in $\mathrm{nA}$ above the blood sugar changings, in response to the glucose injected i.v. Again, the delay between the nadir of the blood sugar increases were recorded in the range of $15-20 \mathrm{~min}$.

All of the animals, were, of course, completely conscious, and after a few days were completely used to eating, responding, caressing and speaking. They were only limited to the extent of the experimental setting. Telemetric recording of the glucose generated energy is already attacked for the next experimental period. Up to now, the life-time of the sensor implanted was never less than 4 days.

If specificity, and, to a certain extent, stability is so much better than thought before, the problem of biocompatibility also looks better than we had expected at earlier periods. With some other new material which had not been tried before, even 3 months implantation s.c. in rats did not result in any major reaction (Fig. 16).

\section{Conclusions}

When we started more than 10 years ago by developing a "closed loop" glucose controlled insulin infusion system it was clear that certain inborn limitations will not be overcome: The regulation was based exclusively on the changes in the blood sugar concentrations, and the insulin supply was completely confined to peripheral, i. e. not to intraportal administration. 


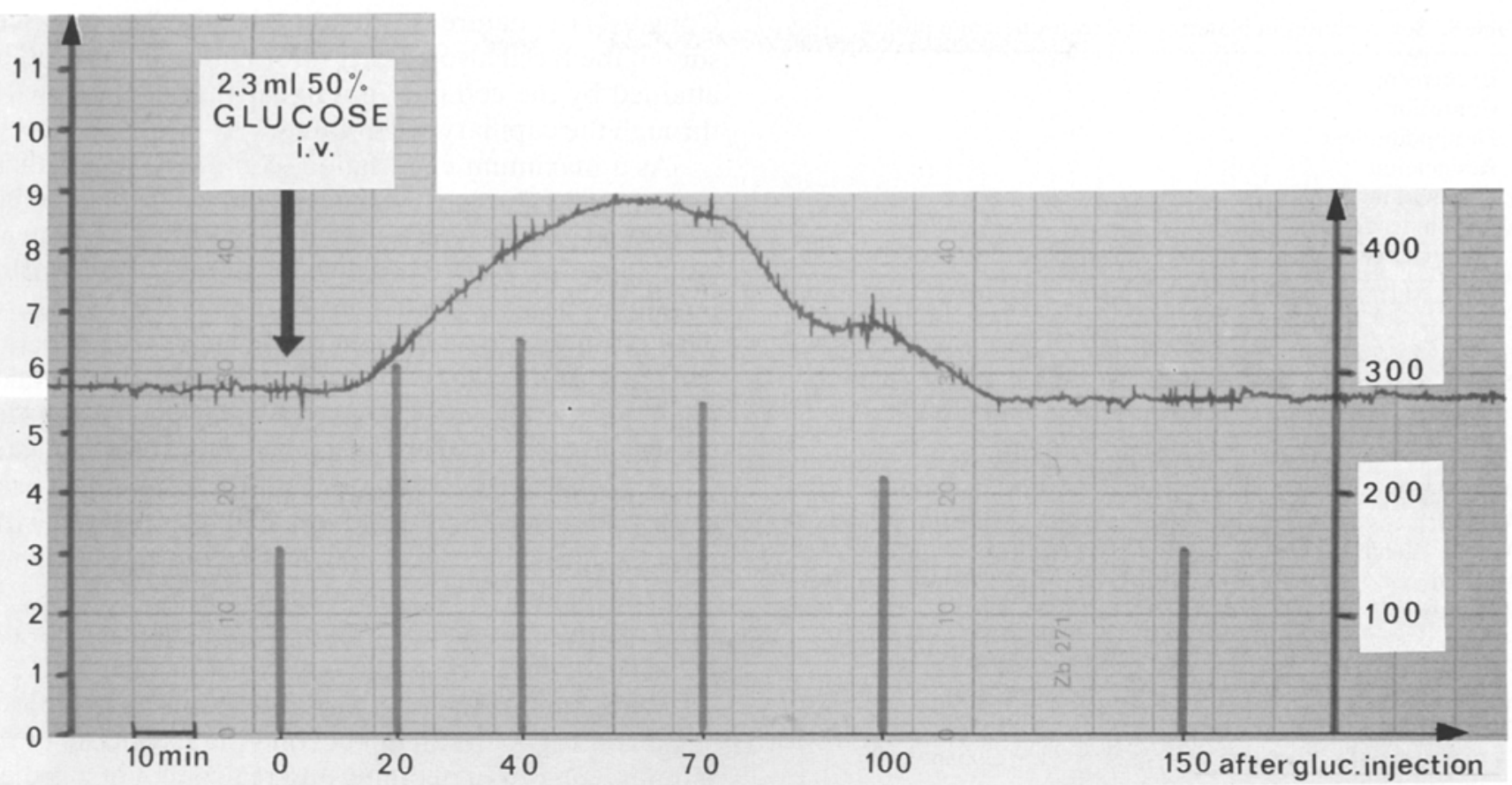

Fig. 15. The "new" glucose sensor implanted subcutaneously in a rabbit: parallelism between blood sugar concentrations (columns) and the current of the glucose sensor (line) with a lag time of about $15 \mathrm{~min}$ shown in an IVGTT (left ordinate: current of the glucose sensor in nA; right ordinate: blood sugar concentrations in $\mathrm{mg} / \mathrm{dl}$ )

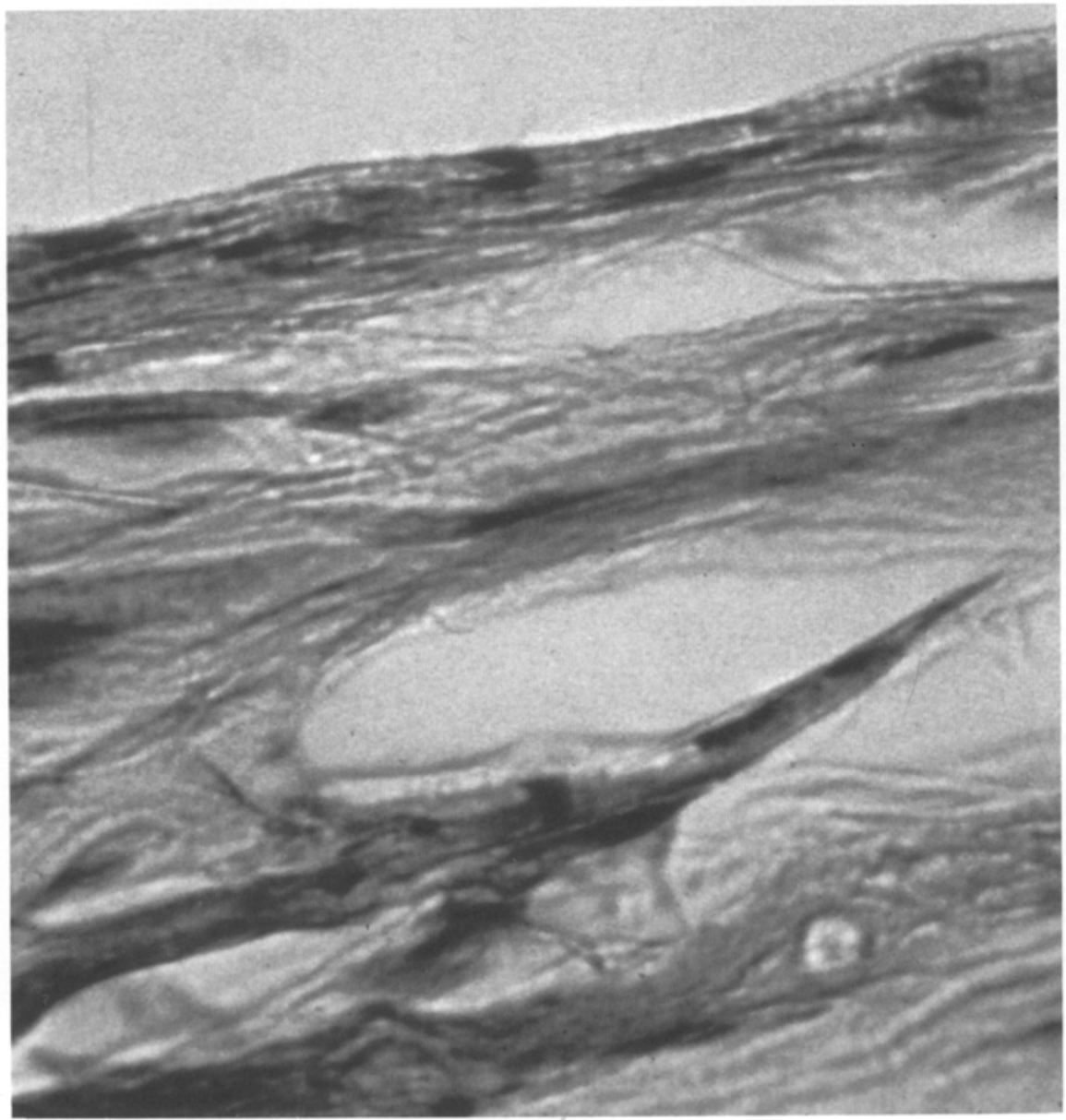

Fig. 16. A biocompatible material implanted in rats 3 months s. c. showed no major tissue reaction (125-fold magnification of a haematoxylin-eosin stained slide) 
Table 5. Seven phases in planning and realization of a project
1. Excitement
2. Confusion
3. Disappointment
4. Resignation
5. Search of the culprit
6. Punishment of the innocent
7. Distinction and honouring of the unconcerned

Table 6. Associates and participants in the work on the artificial endocrine pancreas (on the left: physicians and engineers; on the right: candidates for a doctor's degree and medical assistants)

\begin{tabular}{ll}
\hline P.Arias & C. Meissner \\
W. Beischer & H.Moll \\
A. H.Clemens & M.Schmidt \\
A.de la Fuente & D.Schock \\
M. Dolderer & T.v.Schrenck \\
W. Kerner & M.Schultz \\
L. Navascues & H. Babli \\
E. F. Pfeiffer & H. Hilbig \\
S. Raptis & C. Rudtke \\
G.Steinbach & R.Schönke \\
G. Y.Tamas & I. Wollmann \\
C.Thum & \\
A.A.Torres & \\
H.Zier & \\
\hline
\end{tabular}

In comparison to the many regulatory factors influencing blood glucose regulation in the normal organism, this already was a major disadvantage of the technical systems, in comparison to the natural regulation.

As discussed above, a number of certain manipulations, as advanced administration of insulin, in connection with the meals, was permitting to keep up with some of these inborn limitations. Hyperinsulinism still had not been completely overcome, in general.

With a delay in the changes in the tissue glucose levels, which have to be added to the delay in the insulin delivery via s.c. or i.p. routes - as long we are not developing techniques for infusing the insulin on a long-term basis directly into a peripheral vein - we are, reliable tissue glucose measurements provided, still 20 to $25 \mathrm{~min}$ behind the rapid blood sugar fluctuations. This will not permit the development of algorithms for automated blood sugar regulations by continuous glucose monitoring as we had done successfully in the presently available AEP in clinical use. We shall have to find the tissues where the constant interplay between blood flow, transport across the capillaries, and the cellular half life, is different from the s.c. or the i.p. area. An entirely new field lies ahead. Hopefully, a certain niche will be found where the information delivered by the tissue glucose content to the sensor comes earlier than in the s.c. and i.p. region. Here, we have to remember the situation around the Langerhans islet, where a special capillary network around the $\mathrm{B}$ cell is providing the information of changes in the blood sugar content $45 \mathrm{~s}$ after injection, i. e. earlier than in other regions of the circulation, as beautifully shown by Dr. Rooth from Sweden at this
Congress, i.e. nature is providing for the "glucose sensor" of the B cell also a faster information than could be attained by the certainly not linear flux of the glucose through the capillary membranes.

As a maximum expectation, complete renormalization of blood glucose levels over $24 \mathrm{~h}$, and postprandially and following exercise, might be provided when overcoming the problem consisting at present of measuring interstitial tissue glucose contents. As a minimum, also with this limitation, constant blood sugar values below $200 \mathrm{mg} \%$ during daily life and also after food intake, might be automatically effected by glucose sensing s.c., and the development of special algorithms for that situation, as well as blood sugar response tests similar to the Type 2 (non-insulin-dependent) diabetic patient without hypoglycaemic reactions. In other words, the Type 1 diabetic patient might be changed by proceeding in such a fashion to a Type 2 diabetic patient, i. e. with minor risks of developing microangiopathic changes.

When predicting the rosy future of automated blood sugar control, I am still not beyond the scepticism of the famous 7 phases in planning and realization of a project (Table 5) where I would like to see us placed just below the number 4-phase, before expecting the unpredictable last 3 .

\section{References}

1. Kruse-Jarres JD, Molnar GD (eds) (1977) Blood glucose monitoring. Horm Metab Res [Suppl Ser] 7:1-157

2. Pfeiffer EF, Thum C, Raptis S, Beischer W, Ziegler R (1976) Hypoglycemia in diabetics. Horm Metab Res [Suppl Ser] 6:112-126

3. Pfeiffer EF, Thum C, Clemens AH (1974) The artificial beta cell a continuous control of blood sugar by external regulation of insulin infusion (glucose controlled insulin infusion system). Horm Metab Res 6: 339-342

4. Pfeiffer EF, Thum C, Clemens AH (1974) Die künstliche BetaZelle: Ein automatisch gesteuertes Insulin-Infusionssystem zur Behandlung von Zuckerkranken. Naturwissenschaften 61: 455-456

5. Albisser AM, Leibel BS, Ewart TG, Davidovac Z, Botz CK, Zingg W (1974) An artificial endocrine pancreas. Diabetes 23:389-396

6. Kraegen EW, Campbell LV, Chia YO, Meler H, Lazarus L (1977) Control of blood glucose in diabetics using an artificial pancreas. Aust NZ J Med 7: 280-286

7. Mirouze J, Selam JL, Pham TC, Cavadore D (1977) Evaluation of exogenous insulin homoeostasis by the artificial pancreas in insulin dependent diabetes. Diabetologia 13: 273-278

8. Kawamori R, Shichiri M, Goriya Y, Yamasaki Y, Shigeta Y, Abe $H$ (1978) Importance of insulin secretion based on the rate of change in blood glucose concentration in glucose tolerance assessed by the artificial beta cell. Acta Endocrinol 87:339-351

9. Sailer D, Berg G (1979) Computer-controlled bedside monitoring and infusion system. Horm Metab Res [Suppl Ser] 8: 45-48

10. Slama G, Klein JC, Delage A, Rottembourg J, Marenani A, Jacobs C (1979) The use of the artificial pancreas in uremic diabetic patients. Horm Metab Res [Suppl Ser] 8: 178-183

11. Kadish AH (1964) Automation control of blood sugar I. A servomechanism for glucose monitoring and control. Am J Med Electronics 3: 82-86

12. Kerner W, Thum C, Tamas G, Beischer W, Clemens AH, Pfeiffer EF (1976) Attempts at perfect normalization of glucose tolerance 
test of severe diabetics by artificial beta-cell. Horm Metab Res 8: 256-261

13. Kerner W, Beischer W, Herfarth C, Pfeiffer EF (1979) Application of an artificial endocrine pancreas in the management of the diabetic surgical patient. Horm Metab Res [Suppl Ser] 8: 159-161

14. Beyer J, Wolf E, Cordes U, Hassinger W (1979) The artificial beta cell (Biostator) in the adjustment of instable diabetics - results after 20 months. Horm Metab Res [Suppl Ser] 8: 127-131

15. Lambert AG, Buysschaert M, Lambotte L (1979) Use of an artificial pancreas as a tool to determine subcutaneous insulin dose in juvenile diabetes. Diabetes Care 2: 256-264

16. Christiansen JS, Svendsen PA, Mathiesen E, Rubin P, Deckert T (1981) Comparison of 24-h insulin requirements in IDDM patients during control by an artificial beta cell and during conventional therapy. Horm Metab Res 13: 537-541

17. Kraegen EW, Chisholm DY, McNamam ME (1981) Training of insulin delivery with meals. Horm Metab Res 13: 365-367

18. Kerner W, Moll U, Navascues I, Pfeiffer EF (1984) Importance of early postprandial insulin delivery in insulin-dependent diabetics. Klin Wochenschr 62: 738-744

19. Kerner W, Schultz M, Schock D, Pfeiffer EF (1982) Variations of insulin requirements in insulin dependent diabetics for meals taken at different times of the day. Horm Metab Res [Suppl Ser] 12: $228-230$

20. Clarke WL, Haymond MW, Santiago JU (1980) Overnight basal insulin requirements in fasting insulin-dependent diabetics. Diabetes $29: 78-80$

21. Kerner W, Navascues I, Torres AA, Pfeiffer EF (1984) Studies on the pathogenesis of the dawn phenomenon in insulin-dependent diabetic patients. Metabolism 33: 458-464

22. Meissner C, Thum C, Beischer W, Winkler G, Schröder KE, Pfeiffer EF (1975) The antidiabetic action of somatostatin-assessed by the artificial pancreas. Diabetes 24:988-996

23. Marliss EB, Murray FT, Stokes EF, Zinman B, Nakhooda AF, Denoga A, Leibel BS, Albisser AM (1977) Normalization of glycemia in diabetics during meals with insulin and glucagon delivery by the artificial pancreas. Diabetes 26: 663-672

24. Schock D, Schultz M, Kerner W, Maier V, Pfeiffer EF (1981) The influence of normoglycemia on serum concentrations of growth hormone, glucagon and free fatty acids in juvenile diabetics. Irsigler K, Kunz KN, Owens DR, Regal H (eds) New approaches to insulin therapy. MTP Press, Lancaster, pp 211-218

25. Hanna AK, Zinman B, Nakhooda AF, Minuk HL, Stokes EF, Albisser AM, Leibel BS, Marliss EB (1980) Insulin, glucagon and amino acids during glycemic control by the artificial pancreas in diabetic man. Metabolism 29: 321-332

26. Horwitz DL (1979) Insulin responses to mixed meals: comparison of an artificial beta cell and normal beta cells. Horm Metab Res [Suppl Ser] 8: 68-71

27. Foss MC, Vlachokosta FV, Cunningham L, Aoki TT (1982) Restoration of glucose homeostasis in insulin-dependent diabetic subjects. Diabetes 31: 46-52

28. Botz CK, Leibel BS, Zingg W, Gander RE, Albisser AM (1976) Comparison of peripheral and portal routes of insulin infusion by a computer-controlled insulin infusion system (artificial endocrine pancreas). Diabetes 25:691-700
29. Schock A, Schultz M, Kerner W, Maier V, Pfeiffer EF (1979) The effect of three days of blood glucose normalization by means of an artificial endocrine pancreas on the concentrations of growth hormone, glucagon and cortisol in juvenile diabetics. Horm Metab Res [Suppl Ser] 8: 93-96

30. Kerner W (1984) Artificial endocrine pancreas and portal insulin pumps: effect of improved glucose control on hormonal and metabolic abnormalities and the development of microvascular complications in Type I diabetes. In: Federlin $\mathrm{K}$, Scholtholt J (eds) The importance of islets of Langerhans for modern endocrinology. Raven Press, New York, pp 189-204

31. Mirouze JJ (1983) Insulin treatment: non-stop revolution. Diabetologia 25: 209-221

32. Lauritzen T, Frost-Larsen K, Larsen HW, Deckert T, Steno Study Group (1983) Effect of 1 year of near-normal blood glucose levels on retinopathy in insulin-dependent diabetics. Lancet 1: 200-204

33. The Kroc Collaborative Study Group (1984) Blood glucose control and the evolution of diabetic retinopathy and albuminuria. A preliminary multicenter trial. N Engl J Med 311:365-372

34. Pfeiffer EF, Kerner W (1979) The impact of insulin infusion systems upon the theory and practice of diagnosis and treatment of diabetes mellitus. In: WaldhäusI WK (ed) Diabetes 1979. Proceedings of the 10th Congress of the IDF. Excerpta Medica, Amsterdam, Oxford

35. Arias P, Kerner W, Zier H, Navascues I, Pfeiffer EF (1984) Incidence of hypoglycemic episodes in diabetic patients under continuous subcutaneous insulin infusion and intensified conventional insulin treatment: assessment by means of semiambulatory 24 hours continuous blood glucose monitoring. Diabetes Care 8: 134-140

36. Clark LC, Lyons C (1962) Electrode systems for continuous monitoring in cardiovascular surgery. Ann NY Acad Sci 102: 29-45

37. Updike SJ, Hicks GP (1967) The enzyme electrode. Nature 214: 986-988

38. Clemens AH, Chang PH, Kerner W, Myers RW, Pfeiffer EF (1977) Development of an electrochemical blood glucose analyzer and new control algorithms for a glucose controlled insulin infusion (artificial beta-cell). In: Bajaj JS (ed) Diabetes. Proceedings of the IX Congress of the International Diabetes Federation. Excerpta Medica, Amsterdam Oxford, pp 481-488

39. Pfeiffer EF, Beischer W, Kerner W (1977) The artificial endocrine pancreas in clinical research. Horm Metab Res [Suppl Ser] 7: 95-112

40. Pozza G, Bosi E, Secchi A, Piatti PM, Touraine JL, Gebet A, Pontiroli AE, Dubernard JM, Traeger J (1985) Metabolic control of Type I (insulin dependent) diabetes after pancreas transplantation. Br Med J 291: 510

Professor E.F.Pfeiffer

Universität Ulm

Postfach 3880

D-7900 Ulm

FRG 